\title{
Necessity for diversity of commercial facilities for daily shopping in residential planning ${ }^{\mathrm{a}}$
}

\author{
Pingli Chen ${ }^{1, b}$ and Yungchi Yen ${ }^{2}$ \\ ${ }^{1}$ Department of Urban Planning and Landscape, National Quemoy University, Taiwan \\ ${ }^{2}$ Center for National Land Development Research, National Cheng Kung University, Taiwan
}

\begin{abstract}
Since the 1990s, the government administrations have thought that supermarkets could replace traditional retail markets as the commercial facilities for daily shopping in Taiwan. However, traditional retail markets remained prosperous. This paper aims to investigate the followings: 1) whether traditional retail markets still play an important role in residents' daily shopping and 2) whether supermarkets and traditional retail markets are actually complementary rather than competitive as commercial facilities for daily shopping. The examination is based on the data regarding married women's daily shopping behaviours in a planned residential area in Taipei from a questionnaire carried out in 2007. Several things are concluded below. First, consumers do not definitely choose the new types of facilities for daily shopping. Second, supermarkets in residential areas may be complementary to traditional retail markets in residents' daily shopping. Third, traditional retail market plays a role beyond acting as the exchange space for goods. Fourth, even though cars are popular in Taiwan, married women still prefer to conduct their daily shopping inside or nearby their neighbourhood unit by walking. This paper suggests it is necessary to maintain diversity rather than to anticipate or limit the type of commercial facilities available for daily shopping in residential planning.
\end{abstract}

\section{Introduction}

Mainstream supermarket chains and hypermarkets such as Carrefour emerged in Taiwan beginning in the 1980s and, originally, government administrators or local planning boards thought supermarkets would be able to replace traditional retail markets. For example, Article 7 of the Taipei Retail Market Management Regulations was amended to develop planned market-lands into public supermarkets in 1990. However, in many cities and rural areas, traditional retail markets remained prosperous.

Many studies with different perspectives have been conducted such as studies focused on the use of hypermarkets [1] and on consumers' habits and interrelated activities in a large downtown shopping centre [2]. In this study we focus on the daily shopping activities of married women to observe their behaviours in traditional retail markets and in the new type of community commercial facilities such as supermarkets and hypermarkets, the former having existed before the introduction of modern urban planning theories and the latter having increased in prevalence since the $1980 \mathrm{~s}$. We aim 1) to discuss

\footnotetext{
${ }^{a}$ The draft version of this paper has been presented at the 3th International Conference on Built Environment in Developing Countries, Malaysia, 2011.

${ }^{\mathrm{b}}$ Corresponding author : piyocu@gmail.com
} 
how married women conduct their daily shopping and how characteristics such as their occupation and children influence them in this activity and 2) to clarify the roles of traditional retail markets, supermarkets, and hypermarkets in married women's daily shopping activities, and 3) to discuss the issues of commercial facilities for daily shopping in residential planning in the future.

The second section deals with the relationships between neighbourhood units, daily shopping and married women by considering different bodies of literature. In the third section, we briefly present an overview of our case study area, the Minsheng Community in Taipei city, anddescribe our research methodology. The fourth section analyses the features of married women's daily shopping activities. Finally, some conclusions are drawn in the last section. We do this not only by reporting the findings but also by discussing their implications for the future of planning in residential environments.

\section{Neighbourhood units, daily shopping, and married women}

The neighbourhood unit is considered to be a popular residential design paradigm, which was conceived by Perry[3] and has been widely used as a design concept in many countries [4]. In Perry's description of the physical attributes of the neighbourhood, local shops were important elements in a neighbourhood unit. Conceptually, these local shops were expected to be on the edge of neighbourhoods, preferably at traffic junctions and close to similar districts of nearby neighbourhoods.

This approach was used in new town developments in many countries. When it was applied in England and Japan, the arrangement of the neighbourhoods was changed from Perry's original plan. The Dudley Report, published by the Ministry of Health in Britain, recommended that the main neighbourhood shopping activities should be within the neighbourhood and should form part of the neighbourhood centre [5]. A similar idea was commonly applied in new town plans in Japan after World War II.

In Taiwan, after World War II ended, the first new town named Chung-Hsin New Village was developed in 1957. The plan of Chung-Hsin New Village referred to the cases in Britain. In ChungHsin New Village, traditional retail markets were established in the centre of neighbourhood units for the residents' daily shopping. After this experimental new town developed, several facilities were legislated to be arranged in neighbourhood units as public facilities in the Urban Planning Act of 1964 in Taiwan. The "market" was one of those facilities, and it aimed to satisfy the residents' daily shopping needs.

Before supermarkets appeared in Taiwan, the term "market" was equivalent to the traditional retail markets. As is literally stated by the word 'traditional', traditional retail markets are areas where booths and stores are located and people sell goods in an age-old way, face-to-face. Every booth and store is small in scale and only provides specific goods, e.g., the butcher, greengrocer, florists or grocery stores. These booths and stores have a complicated relationship in that they complement and compete with each other in the market where they are located.

As supermarkets became increasingly popular, the consequences started to change. There was an official research project regarding community facilities planning undertaken in 1989 by the Department of Urban and Housing Development in CEPD. The study claimed that traditional retail markets and supermarkets should be considered together when developing a residential community because people had changed their everyday shopping behaviours[6]. Although this claim was based on case studies of private sector development rather than on the shopping behaviours or needs of the residents, the idea "to replace the traditional retail markets with supermarkets" has gradually permeated the bureaucracy. The amendment of the Taipei Retail Market Management Regulation mentioned above reflects this phenomenon. Supermarkets and their suppliers, are emerging as key policy and political debates in many other developing countries [7].

According to Christaller's central place theory, accessibility can be used to explain phenomenon related to daily shopping because grocery and household items are defined as low order goods. Daily shopping is often regarded as a local activity. However, such a local activity is actually an important part of our everyday lives and sometimes not as simple as Christaller states. For example, Wang and Lo examined the preferences of Chinese immigrants for the fast-growing Chinese supermarkets versus 
the competing mainstream supermarket chains and found that ethnic affinity had a stronger effect on immigrants' choice of shopping venue than economic rationality such as considerations of accessibility[8]. The authors therefore claimed that grocery shopping has socio-cultural meaning for immigrants and that the social use of ethnic shopping spaces indicates that immigrants are not only consumers in ethnic shopping places but also participants in this unique ethnic retail environment.

Actually, activities such as domestic duties and childcare are part of the daily routine for married women and influence their movements in everyday lives. Therefore, married women may have different life patterns than married men. It was discovered that married women have to make more trips and spend more time buying necessities on weekdays than married men do[9]. Their study also showed that married women with babies or infants will go out more frequently but spend a shorter time out than other married women do.

Beyond these discussions, we speculate that such a "taken-for-granted" activity is more intricate and interesting than previously thought and should be discussed in more detail. Actually, many studies starts to rethink the role of traditional retail markets[10] [11]. We will examine whether it is appropriate to replace the traditional retail markets with supermarkets.

\section{Study methodology}

\subsection{Summary of case study area}

We chose the Minsheng Community, a planned residential area in Taipei city, as our case study area for the following reasons: 1) it was well-planned with the help of foreign planners in 1960s and offered new ideas about how a good residential area should be designed during that period; 2) the population in this community underwent a high-growth period during 1970s-1980s, and it is now in a stable state in terms of private development, population growth, and the life patterns of the residents; and 3) there are sufficient and various facilities for everyday life in this area and it is appropriate for observing the shopping behaviours and preferences of residents. Figure 1 shows the location of the Minsheng Community in Taipei City.

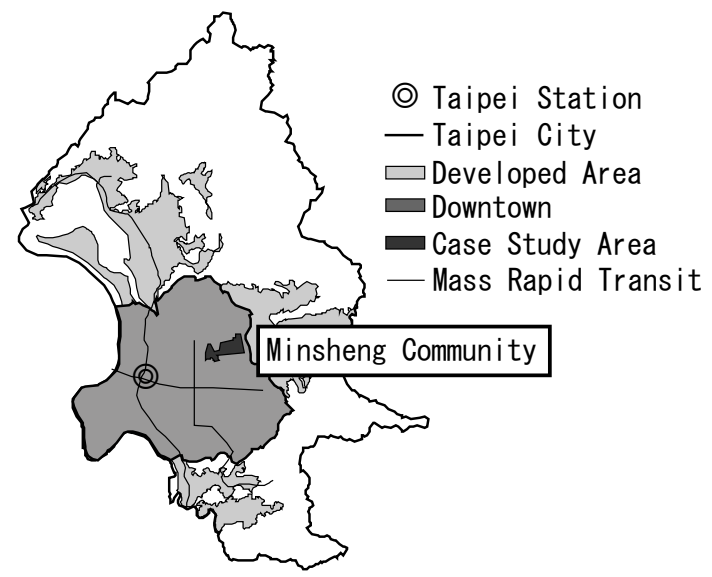

Figure 1. Location of the Minsheng Community in Taipei.

The Minsheng Community was developed in the 1960s as the model project for residential land adjustment, with help from the United States in terms of money and professional knowledge of planning. Because it was close to downtown Taipei City, the housing was mainly in medium-rise apartment. In the initial plan, the Minsheng Community was separated into seven neighbourhood units. The size of the neighbourhood unit was about 8 to 16 ha, which is small due to the high density in this area. There were two centre areas set in the Minsheng Community and therefore, two neighbourhood clusters that are formed by three to four neighbourhood units can be identified. Figure 2 shows the 
original detail plan of the Minsheng Community in 1968. The detail plan has changed for several times and version of 1988 was the latest one when our study started.

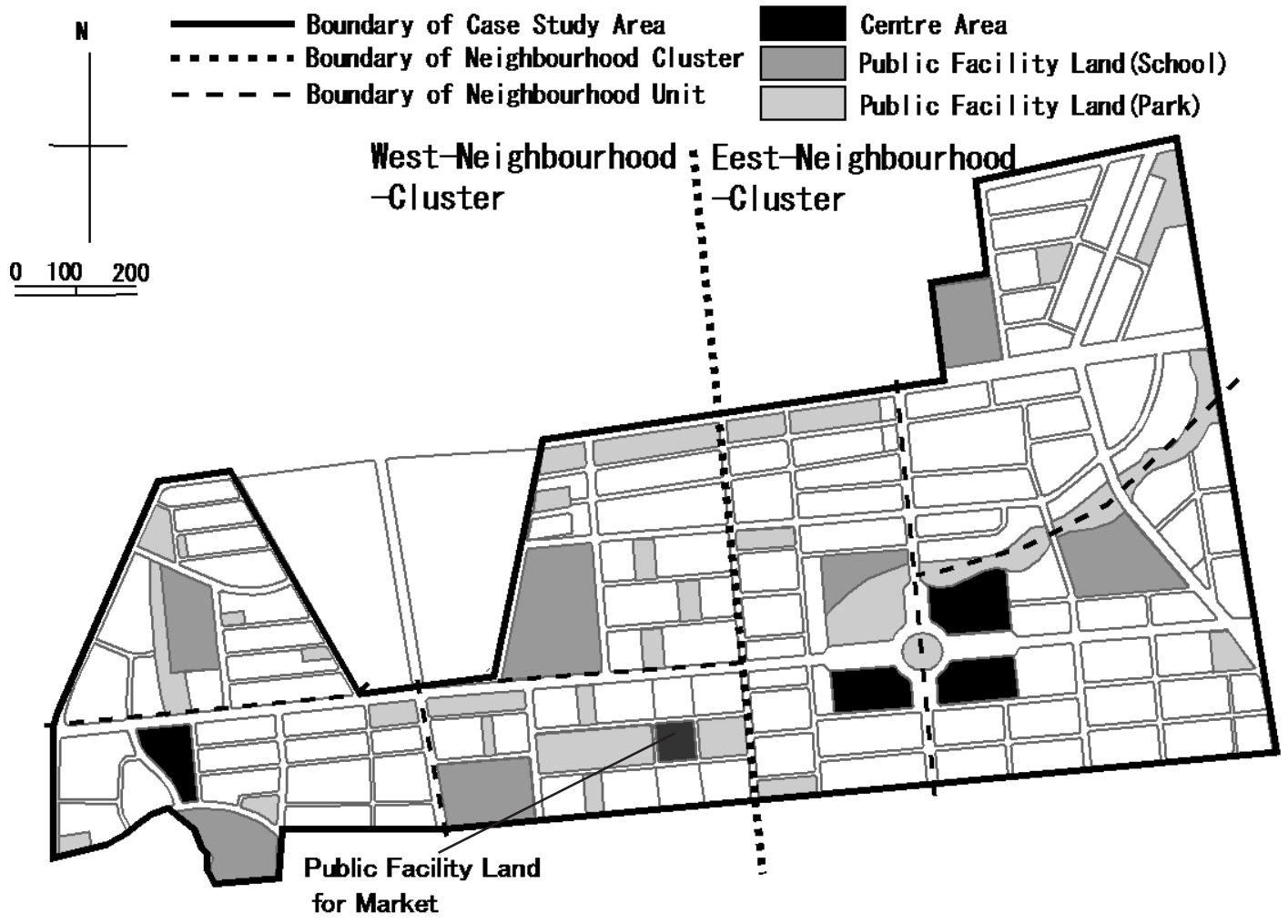

Figure 2. The original detail plan of the Minsheng Community in 1968.

Living facilities were arranged at two levels: the neighbourhood unit level and the neighbourhood cluster level. At the neighbourhood unit level, there was one primary school and several parks. The other facilities, including those for daily shopping, were arranged at the junction of the neighbourhood units to serve more people at the neighbourhood cluster level. Due to the small size of the neighbourhood units, both neighbourhood units and neighbourhood clusters were in walking distance of necessary facilities. The terrain was flat and it was possible to walk to the facilities at the neighbourhood cluster level or to go there by bicycle. Although supermarkets were still a new type of shopping facility in many countries and had not appeared in Taiwan yet in the 1960s, the commercial facilities for daily shopping in the Minsheng Community were assumed to be supermarkets due to the suggestion of the foreign experts. However, to pander to the shopping habits of residents at that time, a block of public facility land for traditional retail market in the middle of the Minsheng Community was planned.

After 40 years, the landscape has changed in the Minsheng Community. As a result of loose zoning regulations and pressure to development land and property in Taipei City, several condominiums have been renovated from medium-rise to high-rise, and there are now banks, clothing stores, restaurants, and sundry shops located not only at central areas but also along the main streets. The hypermarket even appears in residential areas. These changes are actually beyond the scope of the planners' expectations.

The residents here are middle-class. The population in 2006 was 55,608, and 20,080 households were located there. A population pyramid of the case study area is shown in Figure 3. Although the Minsheng Community has developed over 40 years, many young people live there and the population is not over-saturated with old people as we usually see in some suburban 'old' new town areas. The reason many move to this community could be that the second-hand housing market is active in 
Taiwan, and the community is attractive because of its good location within TaipeiCity. The proportion of those who are over 65 years old here is $12.0 \%$, which is close to the rate of $11.64 \%$ in Taipei City. This fact also reflects the number of new families moving into the Minsheng Community. However, because of the large number of elderly citizens in Taiwan, established communities such as the Minsheng Community face a demographic shift, and this indicates the importance of considering the needs of residents in different stages of the family life cycle.

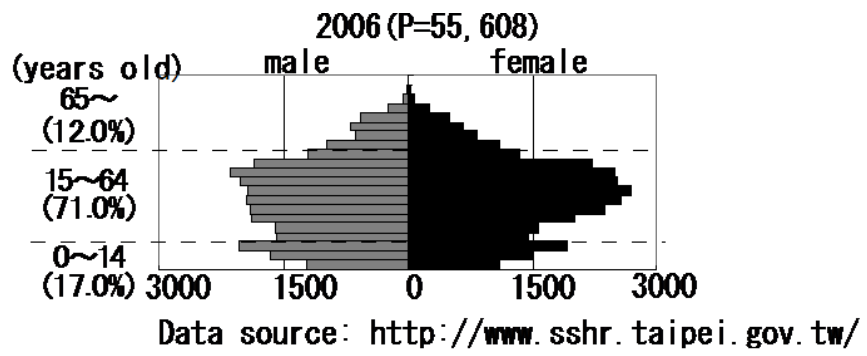

Figure 3. Population pyramid of case study area.

\subsection{Commercial facilities for daily shopping in case study area}

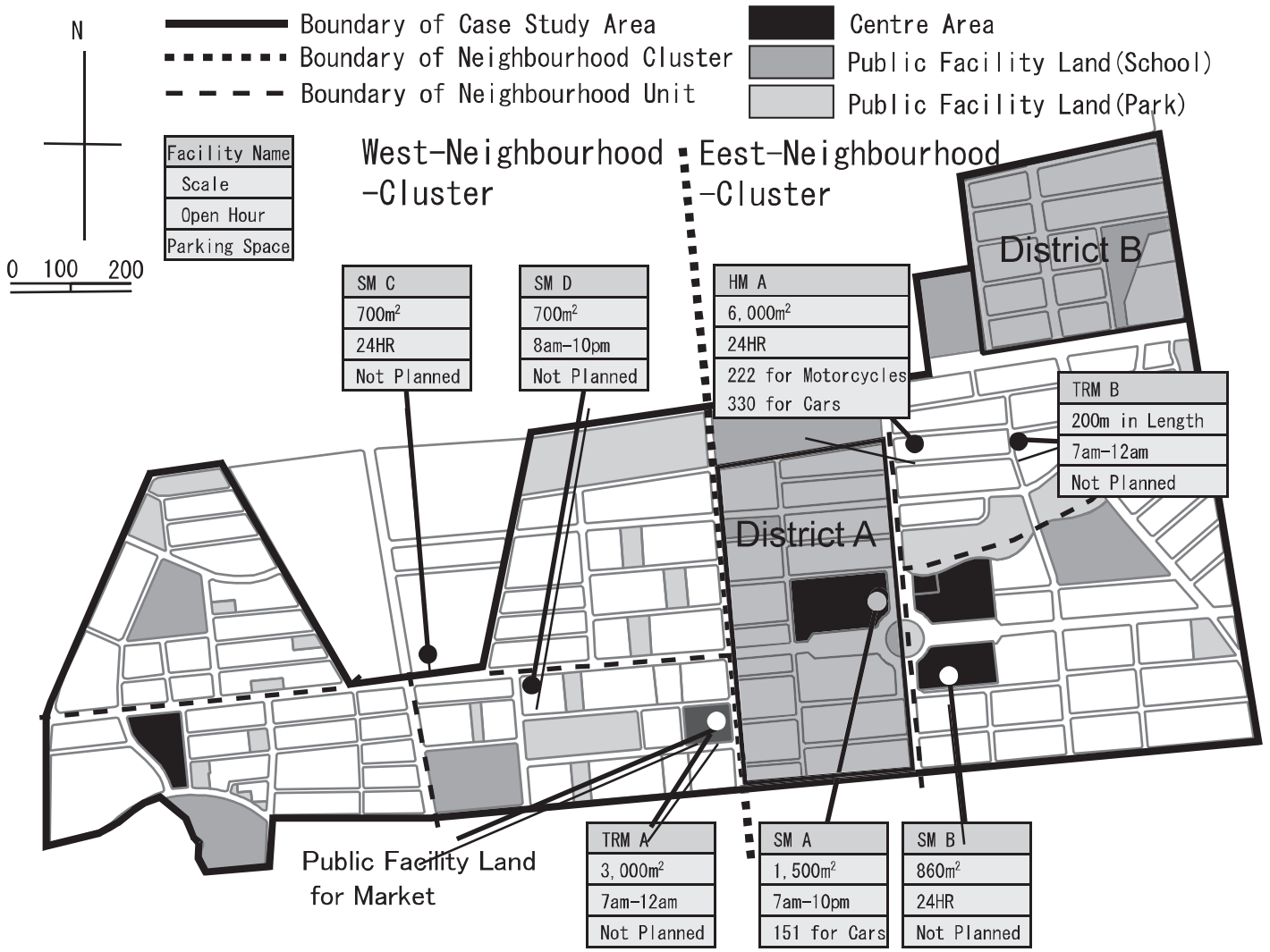

Figure 4. The information and location of commercial facilities.

In this study, we focus on three kinds of commercial facilities for daily shopping: traditional retail markets, supermarkets, and hypermarkets. From the pilot survey, which we will explain in the next section, we found that most married women do their daily shopping inside of the Minsheng 
Community. Therefore, we will chiefly describe the commercial facilities for daily shopping inside of the community. During our survey time period in 2007, two traditional retail markets, five supermarkets, and one hypermarket were located in the Minsheng Community. The information and location of these facilities are shown in Figure 4.

Traditional retail market A (TRM A) was planned while traditional retail market B(TRM B) was spontaneous. The former is a building with several booths inside. The latter, however, is formed by shops on the first floor of the buildings and booths in front of these buildings along the residential streets. Most boothes and shops in these two markets are open in the morning and close before 14:00. Before the first supermarket appeared in 1989, these two traditional retail markets supplied the residents with what they needed in their everyday lives.

Due to the growth of new commercial facilities for daily shopping such as supermarkets and hypermarkets in the urban residential area since the 1990s, the environment for daily shopping in the Minsheng Community has greatly changed. Two supermarkets are located in the east centre area where commercial facility placement was anticipated in the plan.Supermarket A (SM A), the publicly operated chain supermarket that opened in 1991, and Supermarket B (SM B), the Japanese-based chain supermarket that opened in 1994. Besides these two supermarkets, Supermarket C (SM C, based in Hong Kong, opened in 1989)and Supermarket D (SM D, based in Taiwan, opened in 2003) are located along the Minsheng East Road, the main street across from our case study area. The Hypermarket A (HM A) is located in the east neighbourhood cluster.

\subsection{Research methodology}

In this study we focus on married women's daily shopping activities. Methodologically, we use a mixed approach to the case study. A survey questionnaire provides quantitative data on married women's daily shopping behaviours in the case study area, and an interview survey provides narratives of married women's daily shopping experiences, their attitudes, their preferences, and their explanations of their behaviours.

The reasons why we choose married women are detailed below. First, married women are usually considered to take care of their families. They perform activities such as housework, child-rearing, looking after aging parents, and purchasing necessities for their families as part of their gender role in many countries. Although the number of women working outside of the home has increased, some studies show that most married women are still responsible for the domestic duties and childcare in Japan, Korea, Taiwan, the United States, and even in Europe [8-13]. The second reason for choosing married women is related to the phenomenon above. It is said that married women's radii are the basis for arranging facilities for everyday lives in residential planning because they are responsible for daily shopping and usually move around[14]. So, we expected that married women would be appropriate in our study because our main purpose is to address the issues of commercial facilities for daily shopping in residential planning.

The questionnaire survey consists of questions concerning how married women use the commercial facilities for daily shopping, including frequency, transportation issues, and items purchased. The survey was conducted from January 15-21, 2007, with a pilot survey conducted earlier to identify the question items and formulate the questions for the formal survey questionnaire. A random sampling technique was applied as follows. First, we chose two neighbourhood units in the eastern neighbourhood-cluster in our case study area - one is close to the centre area (District A) and another is far from it (District B). The location of District A and District B is shown in Figure 4. Then, we listed all of the address numbers (including the floors) in these two neighbourhood units by site investigation. Third, we took each household at an interval of three numbers as our samples and chose 1,168 households. All of the married women in these chosen households were asked to answer the questionnaire. We ultimately gathered 162 samples for our analysis. Because the data necessary for our study are mostly categorical data, we have used the Chi-square test and Fisher's exact test to analyse the relationships between married women's attributes and their activities. 
The interview survey was held during January 2008. We used snowball sampling to choose eight married women in District A and five married women in District B as our interviewees. The attributes of the interviewees are shown in Table 1.

Table 1. Attributes of interviewees.

\begin{tabular}{|c|c|c|c|c|c|}
\hline \multicolumn{2}{|c|}{ Residential District } & District A & & District B & \\
\hline \multicolumn{2}{|c|}{ Occupation } & $\begin{array}{c}\text { Career } \\
\text { woman }\end{array}$ & Housewife & $\begin{array}{c}\text { Career } \\
\text { woman }\end{array}$ & Housewife \\
\hline \multirow{3}{*}{ Family Life Cycle } & Child-rearing Period & $\mathbf{A 1}$ & $\mathbf{A 2 ,} \mathbf{A 3}$ & $\mathbf{B 1}$ & $\mathbf{B 2}$ \\
\cline { 2 - 6 } & Post-child-rearing Period & $\mathbf{A 4}$ & $\mathbf{A 5}, \mathbf{A 6}$ & $\mathbf{B 3}$ & $\mathbf{B 4}$ \\
\cline { 2 - 6 } & Elderly Period & $\mathbf{A 7}$ & $\mathbf{A 8}$ & & B5 \\
\hline
\end{tabular}

\section{Results}

\subsection{Individual and family attributes}

In this study, we assume that married women's everyday lives are constrained by their occupation and family life cycle according to the theoretical arguments of family life cycle [8, 15-18].

We define the categories of occupation as 'career women' and 'housewives'. Career women are defined as the women who have paid jobs while housewives do not. We define the categories of family life cycle as 'child-rearing period', 'post-child-rearing period', and 'elderly period'. The 'childrearing period' women mean the women who have at least one young child. Our study defined a young child as ranging in age from newborns to elementary school students (0-12 years old). The feature in this period is the double pressure from domestic duties and child-rearing responsibilities. Although married men have begun to become conscious of the importance in sharing housework with their wives, married women are still mainly responsible for these burdens in households in Taiwan. The 'post-child-rearing period' women mean those who are under 65 years old and their youngest child is older than 13 years old. The married women in this period still have to take care of their children, but the burden is lighter compared to the child-rearing period. The 'elderly period' for women refers to those who are over 65 years old. During this period, married women are relieved of the burden of child rearing (although some have started to take care of their grandchildren). However, as their health condition becomes feeble, they may have different needs in their daily lives. The distribution of the respondents is shown in Table 2.

Table 2. Cross table of occupation and family life cycle.

\begin{tabular}{|c|c|c|c|c|}
\hline \multicolumn{2}{|c|}{} & \multicolumn{2}{c|}{ Occupation } & \multirow{2}{*}{ Total } \\
\hline \multirow{3}{*}{ Family Life Cycle } & Housewives & Career Women & \\
\cline { 2 - 5 } & Child-rearing Period & 16 & 45 & $61(37.7 \%)$ \\
\cline { 2 - 5 } & Post-child-rearing Period & 44 & 36 & $80(49.4 \%)$ \\
\cline { 2 - 5 } & Elderly Period & 18 & 3 & $21(12.9 \%)$ \\
\hline \multicolumn{2}{|c|}{ Total } & $78(48.1 \%)$ & $84(51.9 \%)$ & $162(100 \%)$ \\
\hline
\end{tabular}

$\chi^{2}=25.11, \mathrm{df}=2, \mathrm{P}=0.000$

Career women and housewives comprise approximately the same proportion of the study population. In the family life cycle, about half of the respondents were in the post-child-rearing period, and respondents in the child-rearing period are also well-represented. Of the respondents, $12.9 \%$ were in the elderly period, which is close to the prevalence of elderly individuals in our case study area. During the child-rearing period, career women are more prevalent than housewives. The percentage of career women becomes lower as the family life cycle period increases. The number of respondents in District A is slightly higher than in District B. The distribution of the family life cycle and occupation in these two districts is not significantly different based on the results of the Chi-square test (Table 3 and Table 4). 
Table 3. Cross table of occupation and residential district.

\begin{tabular}{|c|c|c|c|c|}
\hline & & \multicolumn{2}{|c|}{ Occupation } & \multirow{2}{*}{ Total } \\
\hline & & Housewives & Career Women & \\
\hline \multirow{2}{*}{$\begin{array}{c}\text { Residential } \\
\text { District }\end{array}$} & District A & 47 & 44 & $91(56.2 \%)$ \\
\hline & District B & 31 & 40 & $71(43.8 \%)$ \\
\hline \multicolumn{2}{|c|}{ Total } & $78(48.1 \%)$ & $84(51.9 \%)$ & $162(100 \%)$ \\
\hline
\end{tabular}

Table 4. Cross table of family life cycle and residential district.

\begin{tabular}{|c|c|c|c|c|c|}
\hline \multicolumn{2}{|c|}{} & \multicolumn{3}{c|}{ Occupation } & \multirow{2}{*}{ Total } \\
\hline & $\begin{array}{c}\text { Child-rearing } \\
\text { Period }\end{array}$ & $\begin{array}{c}\text { Post-child-rearing } \\
\text { Period }\end{array}$ & $\begin{array}{c}\text { Elderly } \\
\text { Period }\end{array}$ & \\
\hline $\begin{array}{c}\text { Residential } \\
\text { District }\end{array}$ & District A & 34 & 43 & 14 & $91(56.2 \%)$ \\
\cline { 2 - 6 } & District B & 27 & 37 & 7 & $71(43.8 \%)$ \\
\hline \multicolumn{2}{|c|}{ Total } & $61(37.7 \%)$ & $80(49.4 \%)$ & $21(12.9 \%)$ & $162(100 \%)$ \\
\hline
\end{tabular}

$\chi^{2}=1.14, \mathrm{df}=2, \mathrm{P}=0.567$

\subsection{The location and types of commercial facilities for daily shopping}

Commercial facilities in residential areas are arranged to satisfy daily shopping needs. Here, we focus on food items and household items, which are purchased frequently in the facilities of interest to support family's daily life. We divide food items into perishables and non-perishables. The former are those with a short shelf life that are likely to decay or go bad quickly such as meat, vegetable, fish and fruit; the latter are those with a relatively long shelf life such as canned food, frozen food and beverage. Household items include tissues, detergents, cleaning goods, and personal hygiene products. Figure 5 shows the results of the survey of commercial facilities for daily shopping. Most of the respondents purchase food items and household items in the Minsheng Community rather than outside of the community, which is similar to the results of the pilot survey.

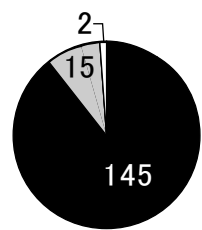

For Food Items

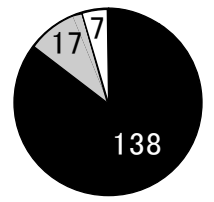

For Household Items

(Total= 162 samples)

Inside Case Study Area $\square$ Outside Case Study Area

$\square$ Rarely Purchasing This Item

Figure 5. Location of daily shopping.

The married women in the Minsheng Community have a tendency to choose more than one commercial facilities for daily shopping. Table 5 shows how many respondents visit specific facilities inside the Minsheng Community. An interesting finding is that although TRM B and HM A are not planned commercial facilities, they are used by most respondents in this survey. The respondents use these two facilities in separate ways, purchasing perishables at TRM B and purchasing nonperishables and household items at HM A.

Although half users of HM A purchase perishables there, these people also purchase these items at TRM B. This means that hypermarkets and traditional retail markets may be complementary facilities because they have different advantages that are considered by married women conducting their daily 
shopping. However, HM A appears to be competitive with SM A and SM B because all of these stores provide non-perishables and household items. Due to less than $25 \%$ of the respondents use SM C and SM D, we will only focus on TRM A, TRM B, SM A, SM B, HM A below.

Table 5. The numbers and percentages of respondents who use specific facilities.

\begin{tabular}{|c|c|c|c|c|c|c|c|c|}
\hline & \multicolumn{2}{|c|}{ Total } & \multicolumn{2}{c|}{ Perishables } & \multicolumn{2}{c|}{ Non-perishables } & \multicolumn{2}{c|}{ Household items } \\
\hline & $\mathbf{N}$ & $\begin{array}{c}\mathbf{\%} \\
(=\mathbf{N} / \mathbf{1 6 2})\end{array}$ & $\mathbf{N}$ & $\begin{array}{c}\mathbf{\%} \\
(=\mathbf{N} / \mathbf{1 6 2})\end{array}$ & $\mathbf{N}$ & $\begin{array}{c}\mathbf{\%} \\
(=\mathbf{N} / \mathbf{1 6 2})\end{array}$ & $\mathbf{N}$ & $\begin{array}{c}\mathbf{\%} \\
(=\mathbf{N} / \mathbf{1 6 2})\end{array}$ \\
\hline TRM A & 64 & $40 \%$ & 44 & $27 \%$ & 13 & $8 \%$ & 1 & $1 \%$ \\
\hline TRM B & 140 & $86 \%$ & 127 & $78 \%$ & 31 & $19 \%$ & 6 & $4 \%$ \\
\hline SM A & 112 & $69 \%$ & 42 & $26 \%$ & 62 & $38 \%$ & 30 & $19 \%$ \\
\hline SM B & 96 & $59 \%$ & 45 & $28 \%$ & 51 & $31 \%$ & 21 & $13 \%$ \\
\hline SM C & 21 & $13 \%$ & 11 & $7 \%$ & 14 & $9 \%$ & 10 & $6 \%$ \\
\hline SM D & 41 & $25 \%$ & 4 & $2 \%$ & 35 & $22 \%$ & 36 & $22 \%$ \\
\hline HM A & 149 & $92 \%$ & 79 & $49 \%$ & 108 & $67 \%$ & 114 & $70 \%$ \\
\hline
\end{tabular}

\subsection{The frequency of commercial facilities for daily shopping}

Figure 6 indicates how frequently respondents visit specific facilities. The frequencies of use of TRM $\mathrm{B}$ and HM A are also higher than those of other facilities. We can say that, for the married women in the Minsheng Community, these two facilities are the major ones for their daily shopping.

Although most of the respondents use TRM B regardless of their family life cycle or occupation, we noticed that married women with different characteristics have different tendencies related to their frequency of using TRM B. Married women in the elderly period use TRM B more frequently than those in the child-rearing period do. Additionally, housewives use TRM B more frequently than career women do. This tendency to use one market over the other implies that women's child rearing responsibility and their paid work constrain the frequency with which they purchased perishables in a traditional retail market.

From the interview survey, we found that although career women and women in child-rearing period appear to shop at the TRM B, the causes of this phenomenon are a bit different. In contract with the supermarkets and hypermarket in our case study area, TRM B has limited open hours in the morning. Some interviewees with careers indicated that they could only go to the traditional retail market on the weekend (interviewee A4 and B3) because it is tiring to go shopping in the early morning and then go to work. The interviewee with a baby (A2) states that she can only go on the weekends when her husband can take care of their baby because the traditional retail market is too crowded to go to with baby. Another interviewee with a baby, A3, even indicated that she does not go to traditional retail markets because it is very dangerous to buy products there when she has to push a baby pram. On the contrary, A3 likes to visit Matsusei, the supermarket. She likes to visit as it provides a clean, orderly, and safe shopping environment for her and her baby. According to the narratives, the constraint to career women is time limitations, but the constraint to women in the childrearing period seems to be the unfriendly shopping environment of the traditional retail market.

From the interview survey, we found there is a different meaning of friendly vs. unfriendly shopping circumstances for the married women in a post-child-rearing period or elderly period. For these married women, traditional retail markets are friendlier than the new commercial facilities. The respondents are accustomed to going to traditional retail markets (especially the TRM B) and have gone for many decades. This habit has been founded on several things: the freshness of the perishables, the diversity of choices, and the familiarity and trust gleaned from the face-to-face selling style. Additionally, many interviewees indicated that going for daily shopping in traditional retail markets is not only a habitual activity of shopping itself, but also it is a way to keep in touch with people because they may meet neighbours there or chat with familiar booth or shops owners. The customers and the owners sometimes exchange their information and even get the benefit of interaction from information exchanges. By such a mechanism, they build a relationship. For example, A8 said she introduced a 
man to the daughter of one customer at a cooperative where A8 often visits, though the two young people had no resulting relationship. These married women in the post-child-rearing period or the elderly period also visit the new commercial facilities. They enjoy the cleanliness and the order there, but they rarely experience human touch and friendliness there as they have when shopping in traditional retail markets.
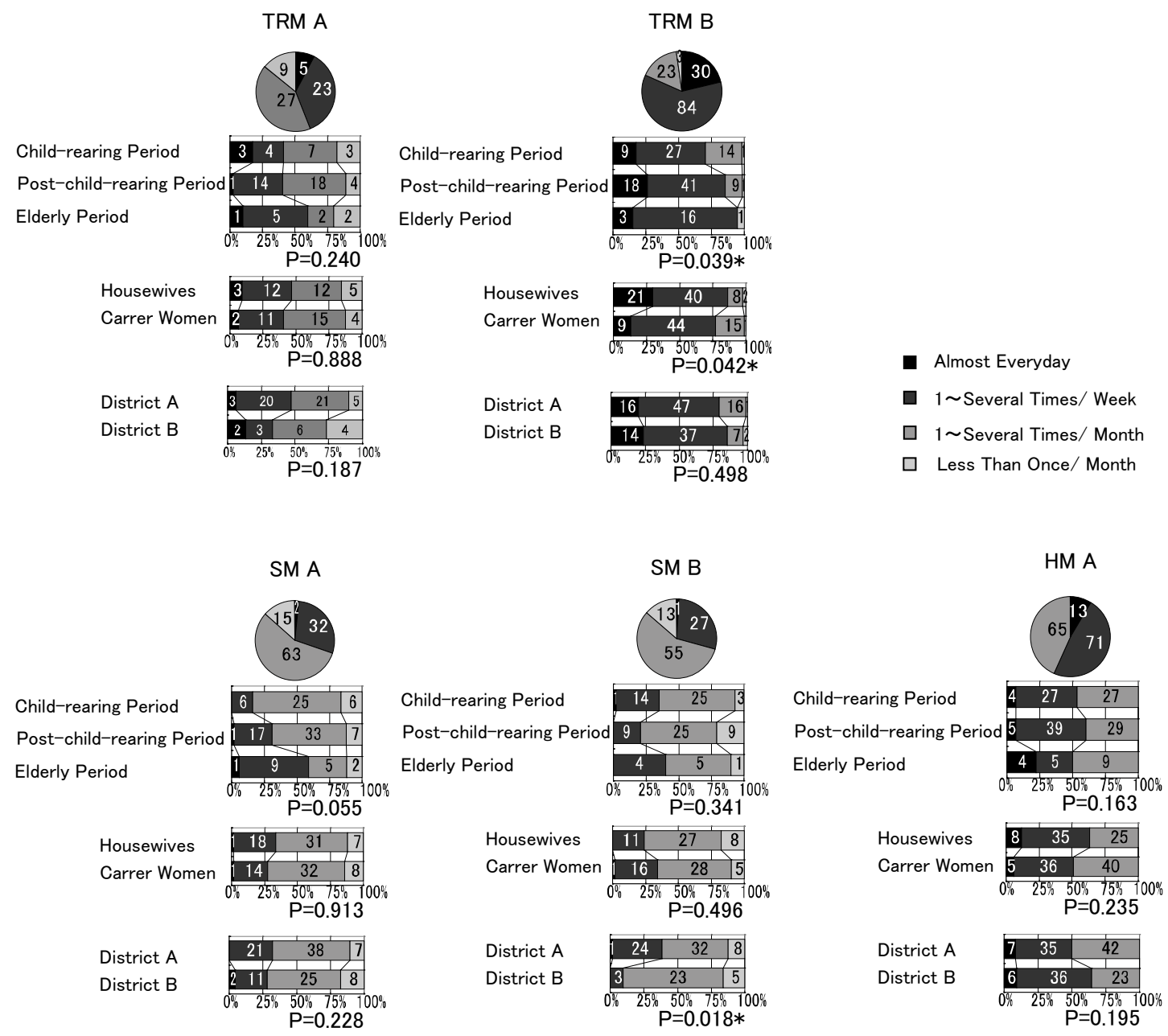

Figure 6. Frequency of visiting specific facilities (Only those who visit are calculated).

\subsection{The transportation to commercial facilities for daily shopping}

As indicated by Figure 7, we can see that most of the respondents walk to these facilities. Married women in the child-rearing and post-child-rearing periods, however, also show a tendency to go by way of other forms of transportation such as bicycle or motorcycle. Those who live in District A usually walk because they are close to the centre area, whereas those who live in District B may walk or go by bicycle or motorcycle due to the relatively long distance to the commercial facilities. However, no matter what occupation these married women pursue, which family life cycle they are in, or where they live, we found that a very small percentage of them go for their daily shopping by car. 


\begin{tabular}{|c|c|c|c|c|}
\hline Child-rearing Period & \begin{tabular}{l|l|l}
3 & 3 & 1 \\
\end{tabular} & Child-rearing Period & \begin{tabular}{|l|l|}
12 & 9 \\
\end{tabular} & \\
\hline Post-child-rearing Period & 20 & Post-child-rearing Period & 10 & \\
\hline Elderly Period & $\begin{array}{cc}10 \\
0 \% \quad 25 \%, 50 \% 75 \% 100 \% \\
P=0.033 * \\
\end{array}$ & Elderly Period & \begin{tabular}{cc|}
19 \\
$0 \%$ & $25 \% 50 \%$ \\
& $P=0.045 \%$ \\
\end{tabular} & $\begin{array}{l}\text { Walking } \\
\text { — By Bicycle }\end{array}$ \\
\hline Housewives & 12 & Housewives & 134 & $\square$ By Motorcycle \\
\hline Carrer Women & $\begin{array}{l}20 \quad 5,6 \\
0 \% \quad 25 \% 50 \% \\
P=0.010 \%\end{array}$ & Carrer Women & 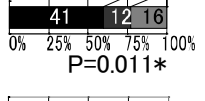 & $\begin{array}{l}\square \text { By Car (herself) } \\
\square \text { By Car (by others) } \\
\square \text { By Other Transportation }\end{array}$ \\
\hline District A & 11 周 & District A & 1810 & \\
\hline District B & 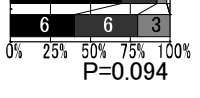 & District B & $\begin{array}{lccc} & 43 & 7 & 10 \\
0 \% & 25 \% & 50 \% & 75 \% \\
& & P=0.235\end{array}$ & \\
\hline & SM A & & SM B & IM A \\
\hline Child-rearing Period & $\begin{array}{ll}58 \\
\end{array}$ & Child-rearing Period & 7614 & Child-rearing Period \\
\hline Post-child-rearing Period & 119. & Post-child-rearing Period & 5 & Post-child-rearing Period 39 \\
\hline Elderly Period & $\begin{array}{ll}17 \\
0 \% & 25 \% \\
& \stackrel{50 \%}{\mathrm{P}}=0.077\end{array}$ & Elderly Period & 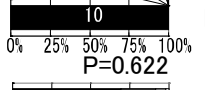 & \begin{tabular}{|c|c|}
17 & 1 \\
$0 \%$ & $25 \% \quad 50 \%$ \\
& $P=0.019 *$ \\
\end{tabular} \\
\hline Housewives & $40 \quad 114$ & Housewives & $32 \quad 103$ & $\begin{array}{ll}43 & 185 \\
\end{array}$ \\
\hline Carrer Women & 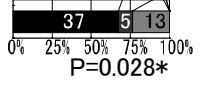 & Carrer Women & $\begin{array}{c}34 \quad 68 \text {. } \\
0 \% \quad 25 \% 50 \% 75 \% 100 \% \\
P=0.346\end{array}$ & 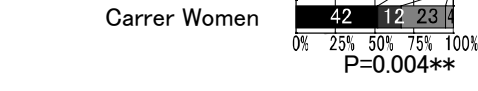 \\
\hline District A & 93 & District A & $\begin{array}{lll}52 & 10 \\
\end{array}$ & \begin{tabular}{|ll}
53 & 19814 \\
\end{tabular} \\
\hline District B & 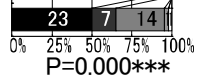 & District B & $\begin{array}{cccc}14 & 6 & 9 \\
0 \% & 25 \% & 50 \% & 75 \% \\
\mathrm{P}=0.000 * * *\end{array}$ & $\begin{array}{ccc}32 & 1120 \% \\
0 \% & 25 \% \quad 50 \% & 75 \% \\
& P=0.012 *\end{array}$ \\
\hline
\end{tabular}

Figure 7. Transportation of visiting specific facilities (Only those who visit are calculated).

As determined from the interview survey, most of the interviewees indicate that they go shopping by walking because the places they go are close to their home. Considering the burden of moving cars, the difficulty of finding a parking space and the various mechanisms of time cost, they prefer to go by walking. Some interviewees mentioned the idea of environmental protection (A1, A2, B1, A5, A6, B4, B5) and the role of exercise for walking to conduct their daily shopping (A5, A6, B5).

\section{Conclusion}

From the analyses in section 4, we can conclude several interesting things below.

First, even if the type of shops where people can conduct their daily shopping changes, it does not mean that consumers will definitely choose the new types of facilities such as supermarkets or hypermarkets. The married women in the Minsheng Community have a tendency to choose more than one commercial facilities for daily shopping at the neighbourhood-cluster level. They still go to traditional retail markets for perishables and go to supermarkets or hypermarkets for non-perishables and household items at the same time. This means that traditional retail markets generally maintain strong advantages as the site for purchasing perishables, whereas supermarkets and hypermarkets play important roles in providing household items. We also found that married women with different characteristics have similar tendencies when choosing facilities but have different tendencies regarding their frequency of use. The different frequency of use comes from the limitations of married women's attributes. Although they have the same tendency in terms of frequency of use, career women have different reasons for reducing the frequency of their visits to the famous traditional retail markets from married women in the child-rearing period. Because different types of commercial 
facilities play different roles in daily shopping, and because different kinds of married women have different needs in choosing commercial facilities even for daily shopping, it is inappropriate to have only one of types of commercial facility when planning a residential area. Additionally, it is important to keep the diversity of commercial facilities for daily shopping to satisfy differing needs of residents rather than to anticipate or limit the type of community commercial facilities in residential planning.

Second, we find that hypermarkets in residential areas may not threaten traditional retail markets and may be complementary to them, though they clearly are competitive with supermarkets and may cause their decline. Indeed, hypermarkets play an important role in providing non-perishables and household items. From the viewpoint of increasing the diversity of commercial facilities for daily shopping, however, it may not be suitable to place hypermarkets in residential areas. At the very least, adequate discussions are necessary.

Third, from the narratives of the interviewees, we find that the traditional retail market plays a role beyond acting as the exchange space for goods. It is also a social space in married women's daily lives. This kind of social functioning is extremely valuable in an isolated society. It is important that planners, since Perry first introduced his residential plan, want to meet the needs of communities. In Japan, some supermarkets have noticed their shortcomings in terms of impersonality and have started to apply face-to-face methods into their selling strategies. It is encouraging to see diverse styles of interaction in commercial facilities. However, it does not mean that supermarkets can replace all the functions of traditional retail markets, and actually, such a replacement is not necessary.

Fourth, even though cars are popular in Taiwan, married women still prefer to conduct their daily shopping inside or nearby their neighbourhood unit by walking. This interesting finding implies a new meaning of neighbourhood unit in the context of environmental protection to reduce $\mathrm{CO} 2$. The third and the fourth findings imply the necessity to re-evaluate the neighbourhood unit and the planned/unplanned facilities therein.

Finally, it is an interesting finding that both of the favourite facilities in our case study are unplanned ones. There seems to be a gap between the residents' preferences and the idea of planners. Although it is not thoroughly discussed in this study, we suggest that further research is needed to fill the gap . Furthermore, we suggest that some research should be undertaken to identify the role of public facility lands for markets in the future.

\section{References}

1. K.K. Chu, L.M. He and H.H.Lin, Journal of the Financial Bank of Taiwan, 36(8), 49-67 (2000)

2. H. Asada, K. Nagai and A. Konno, Journal of the City Planning Institute of Japan, 26, 889-894 (1991)

3. C.A. Perry, The Neighborhood Unit in Regional Survey of New York and Its Environs (Tokyo, 1975)

4. T. Banerijee and W. Baer, Beyond the NeighborhoodUnit: Residential Environments and Public Policy(U.S.A., 1984)

5. A. Goss, Town Planning Review, 32, 66-82 (1961)

6. Department of Urban and Housing Development in CEPD, A Research on improving the quality of environment in urban residential community and planning of community facilities(Taiwan, 1989)

7. T. Reardon and R. Hopkins, The European Journal of Development Research, 18(4), 522-545 (2006)

8. L. Wang and L. Lo, Environment and Planning A, 39, 684-699 (2007)

9. Y. Arai, T. Kawaguchi, K. Okamoto and H. Kamiya, Journal of the City Planning Institute of Japan, 24, 373-378 (1989)

10. S. Gonzalez and P. Waley, Antipode, 45(4), 965-983 (2013)

11. J. Smith, D. Maye and B. Ilbery, Area, 46(2), 122-128 (2014)

12. K. Sechiyama, Gender (Japan, 1994) 
13. Department of Budget, Accounting and Statistics, Taipei Government,Taipei City Statistical Yearbook 2006 (Taiwan, 2007)

14. G.S. Becker, A Treatise on the Family (U.S.A., 1991)

15. S. Hanson and P. Hanson, Transportation, 10, 165-183 (1981)

16. N. Gergson and M. Lowe, Sociological Review, 41(3), 475-505(1993)

17. H. Dohi and S. Suzuki, New Architecture Series 20 Residential Area Plan (Japan, 1985)

18. E.M. Duvall, Family Development (U.S.A., 1971)

19. K. Morioka, Changes of Modern Family (Japan, 1993)

20. T. Sakamoto and K. Kinoshita, Family Sociology- Fundamentals and Applications (Japan, 2001)

21. M. Yamashita, M. Baba, C. Miyahara and Y. Sakurai, Journal of the City Planning Institute of Japan, 41(3), 659-664 (2006) 